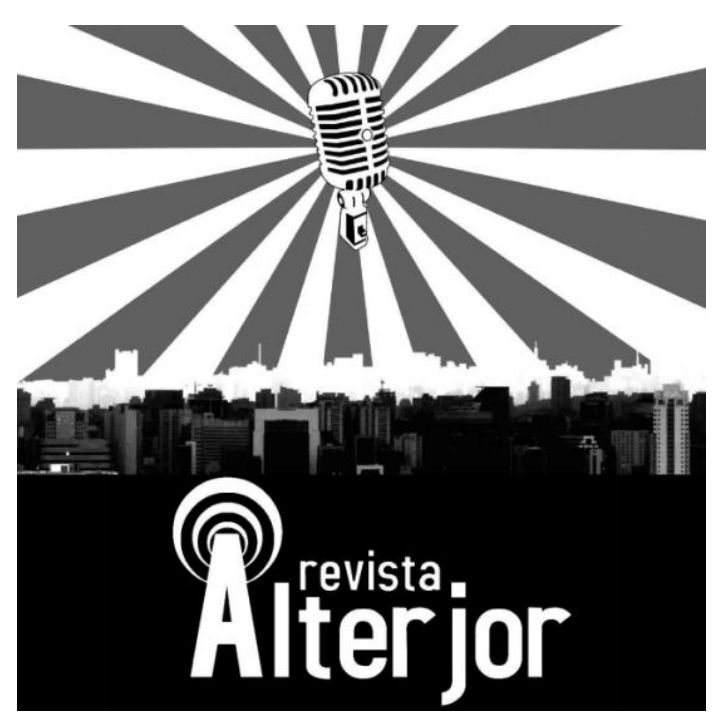

ENTREVISTA

\title{
FAUSTO SALVADORI - DEBATES SOBRE FINANCIAMENTO E AUTONOMIA EDITORIAL NA MÍDIA INDEPENDENTE: 0 MODELO DE ORGANIZAÇÃO DA PONTE JORNALISMO
}

\author{
Jaqueline Suarez Bastos ${ }^{1}$
}

\begin{abstract}
RESUMO: Fausto Salvadori é jornalista e um dos fundadores da Ponte Jornalismo, um coletivo de mídia independente fundado em 2014, especializado em Segurança Pública e Direitos Humanos. Em entrevista, ele explica o modelo de organização adotado pelo grupo, discutindo também temas como financiamento e autonomia editorial. Alinhado a compreensão de independência assumida pelo coletivo, a Ponte tem como base a diversificação das fontes de recurso e uma estrutura organizativa menos hierarquizada e mais humanizada. Registrada como uma ONG, o objetivo final não é a obtenção de lucro, mas sim garantir a sustentabilidade econômica do projeto.
\end{abstract}

PALAVRAS-CHAVE: Mídia independente. Ponte Jornalismo. Jornalismo digital. Modelo de organização. Independência editorial.

ABSTRACT: Fausto Salvadori is a journalist and one of the founders of Ponte Journalism, an independent media collective founded in 2014, wich is specialized in Public Security and Human Rights. In interview, he explains the organizational model applied by the group and also discusses topics like funding and editorial autonomy. Aligned with the Collective's understanding about independence, Ponte is based on the diversification of funding sources, and also a less hierarchical and more humanized organizational structure. Registered as a Non-Governmental Organization, Ponte's ultimate goal is not to make profits, but to ensure the economic sustainability of the project.

KEYWORDS: Independent media. Ponte Jornalismo. Digital Journalism. Organizational model. Editorial independence.

\footnotetext{
${ }^{1}$ Mestranda do Programa de Pós-graduação em Mídia e Cotidiano (PPGMC) da Universidade Federal Fluminense (UFF). Niterói | RJ | Brasil. Bolsista Capes. Integrante do Centro de Pesquisas e Produção em Comunicação e Emergência (Emerge/UFF). ORCID: 0000-0002-5566-1709. E-mail: suarez.jaque@gmail.com.
}

Revista ALTERJOR

Grupo de Estudos Alterjor:Jornalismo Popular e Alternativo (ECA-USP)

Ano Io Volume ol Edição 23 Janeiro-Juho de 2021

Avenida Professor Lúcio Martins Rodriģues, 443, Cidade Universitária, São Paulo, CEP: 05508-020 


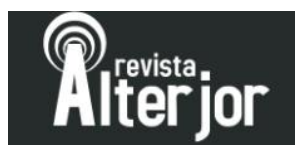

\section{INTRODUÇÃO}

A Ponte Jornalismo é um coletivo de mídia independente criado em junho de 2014 na cidade de São Paulo, especializado na cobertura de Segurança Pública e Direitos humanos. O projeto nasceu a partir de uma proposta da Agência Pública, que reuniu jornalistas investigativos de grandes veículos para produção de uma série de reportagens sobre o tema. Durante o processo, o desejo de criar um espaço específico para continuar fazendo esse trabalho ganhou força, dando início à Ponte. Dos 16 jornalistas fundadores, Fausto Salvadori é um dos poucos que ainda permanece no projeto. Atualmente, faz parte do núcleo estratégico e desempenha uma função semelhante a um diretor de redação.

Antes da Ponte, Fausto trabalhou em publicações comerciais, como Metro, Folha de São Paulo, Vice, Trip, Revista Adusp, Galileu, entre outras. Desde 2014, mantem suas atividades na mídia independente, concomitantemente, ao seu trabalho na Câmara Municipal de São Paulo. No dia a dia da Ponte, Fausto é responsável por coordenar os repórteres e o que será produzido, além de editar as matérias. Segundo ele, a insatisfação com a forma como a grande mídia cobria - e cobre ainda hoje - as histórias relacionadas à Segurança Pública no Brasil é um dos grandes motores para a criação da Ponte Jornalismo. "Havia a necessidade de se fazer uma cobertura de segurança pública preocupada com direitos humanos, preocupada em falar sobre a violência a partir de outra perspectiva, do olhar de quem é vítima dessa violência, do olhar da população negra, pobre e periférica".

\section{ENTREVISTA}

JAQUELINE SUAREZ: Muitas iniciativas de mídia independente surgem e somem rapidamente, sem conseguir passar da fase inicial. Como foi o começo da Ponte Jornalismo? Como foi esse caminho entre o surgimento da ideia até a Ponte se tornar uma proposta concreta e viável?

FAUSTO SALVADORI: A primeira fase da Ponte é uma fase heroica, digamos assim. Todo mundo trabalhando em outros locais. Alguns achavam que a Ponte poder se tornar 


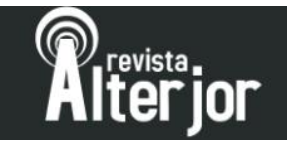

viável em pouco tempo, o que não aconteceu. Viável no sentido econômico. Nesse começo, todos tinham outros empregos e faziam a Ponte nos seus horários vagos, o que significava que ninguém tinha horário vago, já que a Ponte preenchia todo o horário livre que a pessoa poderia ter. Havia uma discussão interna de até que ponto a gente deveria ou não se profissionalizar, se a Ponte deveria ou não ganhar dinheiro. Tinha gente que defendia que a gente tinha que ficar fazendo reportagem sem ganhar mesmo, quase como uma missão. E, tinha um pessoal, especialmente que vinha da periferia, que falava que a gente ficasse sem pagar ninguém, as pessoas que realmente precisam trabalhar para se manter nunca estariam dentro da Ponte. Hoje eu percebo muito essa visão, inclusive um problema que a gente tem na Ponte, que é a falta de diversidade racial. Gênero nunca foi problema, a gente sempre teve muitas mulheres na Ponte, mulheres em postos importantes. Pode parecer paradoxal, mas é real: a falta de dinheiro da Ponte é, justamente, o que elitiza ela, porque enquanto a Ponte não tiver dinheiro só quem tiver alguma condição vai poder participar. Tem outro problema em não se profissionalizar: a qualidade da apuração. Se você só pode trabalhar nas horas vagas, você não vai, por mais que você tenha todo amor, você não consegue se dedicar como deveria à suas pautas. Um exemplo: a gente começa a ser visto por essência como um veículo que cobre abusos do Estado, então se começa uma ação policial em alguma favela e as pessoas de lá acionam a gente, na hora que elas acionam está todo mundo trabalhando em seus empregos e não tem como irmos até o local. Ou seja, o fato de você não ser profissional atrapalha na hora de fazer um bom trabalho. Foram uns três anos para a gente sair dessa fase heroica e entrar numa etapa de profissionalização, que acontece a partir do lançamento de uma campanha de financiamento coletivo.

JAQUELINE SUAREZ: A questão financeira costuma ser o maior desafio para as iniciativas independentes. A Ponte hoje é economicamente viável? Quais são as fontes de recursos do coletivo?

FAUSTO SALVADORI: Em 2017, a gente lança esse programa de financiamento coletivo, que se chamava Fortaleça a Ponte. A gente faz o crowdfunding e consegue o 


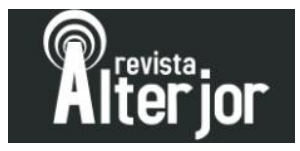

apoio de 788 pessoas, arrecadamos quase $\mathrm{R} \$ 75$ mil reais, vindos do apoio de gente como Chico Buarque, Emicida... Além de mostrar a força que a gente tinha, rendeu uma grana muito boa para a gente usar. Isso já começa a se mostrar o início de uma fase de profissionalização. Junto a isso vem o primeiro grande financiamento vindo direto de uma fundação, no caso foi da Open Society Foundation. Além disso, em 2018tem a entrada de uma pessoa muito importante que é Maria Elisa Muntaner. Ela não é Jornalista, graças a Deus, e só por acaso ela é minha esposa. É ela que vai, finalmente, fazer um processo de profissionalização e formalização da Ponte. Então, a Ponte passa a existir como pessoa Jurídica, passa a ter contador, passa a ter controle de gastos e ter também todo o arcabouço legal e administrativo necessário pra tocar a existência de um site. Então, a partir de 2018 a gente passa a trabalhar remunerando uma parte da equipe. A gente passa a contar com uma estrutura de dois jornalistas, que em 2019 se tornam três. A gente também começou, recentemente, a fazer projetos especiais e vender conteúdo para outros veículos, o que também rende remuneração para parte da equipe e até para colaboradores eventuais. A Open Society renova o apoio pra gente e também conseguimos um financiamento, agora em um programa de aceleração chamado velocidade, um programa feito pela Sembramedia. Agora em 2020, a situação que estamos atualmente, temos três fontes de rendas principais: o Crowdfunding, que é recorrente dos leitores, dos membros; o financiamento por meio de Grant, especialmente da Open Society; e os recursos obtidos por meio de venda de conteúdo. Eu não mencionei, mas eu acho que é bom ficar claro que a Ponte se organiza como ONG, a gente é uma associação civil sem fins lucrativos. Isso significa que a gente não tem o objetivo de lucro, a gente tem o objetivo de tornar o projeto sustentável, acho que isso é importante.

JAQUELINE SUAREZ: A Ponte começou com 16 pessoas e hoje, na aba do Quem somos no site, constam dez nomes. Eu posso entender que essa é a equipe fixa da Ponte, correto? O grupo todo é remunerado ou apenas uma parte? Como ocorre essa decisão? 


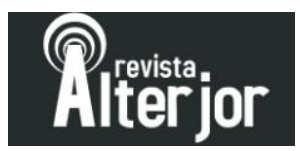

FAUSTO SALVADORI: Como funciona a remuneração da Ponte, você tem a remuneração da equipe fixa, para começar. São três jornalistas hoje em dia, uma editora e dois repórteres, eles são remunerados, são assalariados e tem dedicação exclusiva à Ponte. Para os demais a remuneração é mais variável, pode ser remunerado por projetos, como é o Junião, por exemplo. Ele tem a função de ser gerente de projetos da Ponte, como membro do grupo estratégico, então ele é remunerado quando está tocando algum projeto que tenha remuneração. Dependendo de como estão os valores a gente consegue remunerar outros membros. No momento que a gente está, como não dá pra remunerar a todos, a gente se concentra em remunerar a equipe de jornalistas fixos que são dedicados exclusivamente à Ponte, os demais são remunerados eventualmente. Só pra ficar claro, no grupo fixo nós temos hoje três repórteres remunerados, assalariados; o grupo estratégico, que é remunerado eventualmente; e tem os colaboradores recorrentes, esses são remunerados, digamos, por serviço. Eles são remunerados quando fazem plantão do final de semana, em feriado ou quando fazem uma cobertura de férias. Ou ainda, quando a gente publica reportagens em veículos externos, que são pagas. Se essa matéria for assinada por alguém que não seja da equipe fixa, essa pessoa é remunerada. Atualmente, somos dez pessoas: o grupo estratégico, o grupo editorial e os colaboradores recorrentes. Temos uma rede bem maior de colaboradores eventuais, que chega a 30, 40 pessoas, mas ai é gente que faz uma matéria hoje e vai fazer a próxima daqui a uns meses, no ano que vem... A nossa ideia é, um dia, ter uma rede de colaboradores ampla, fazendo matérias de várias partes do Brasil e sendo remunerada cada vez que fizer uma reportagem.

JAQUELINE SUAREZ: Vocês têm uma redação física? Algum espaço onde a equipe possa se reunir, trabalhar e se encontrar presencialmente?

FAUSTO SALVADORI: A gente fica em um coworking, um espaço compartilhado de trabalho que fica em Pinheiros. É um espaço de elite, sem dúvidas, mas tem segurança. Um dos motivos que nos levou a ir para lá foi a vitória do Bolsonaro, a gente estava bastante preocupado com o que ia ser esse governo, então a gente achou bom ficar perto 


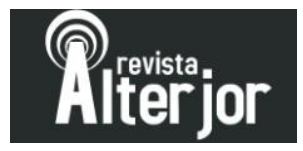

de gente rica, porque gente rica protege. A polícia não vai invadir, não vai chegar ameaçando naquele prédio... E, é de fato uma preocupação real. Quando a gente começou éramos tão inexperientes que colocamos o nosso endereço da redação no site. A polícia foi lá algumas vezes, entregavam intimação, aparecia gente ameaçando, intimidando... Então, hoje em dia a gente fica mais esperto. O nosso endereço oficial, que aparece na documentação, é de um escritório virtual que fica na Avenida Paulista, onde a gente nunca põe os pés. Se alguém chegar procurando nesse endereço não vai nos encontrar lá. Nossa redação física real é um ambiente mais protegido, que é onde ficam os três repórteres da equipe fixa. Uma vez por semana a gente faz uma reunião presencial com todos, toda a equipe, essas 10 pessoas. Excepcionalmente agora tem sido online por causa da Covid-19.

JAQUELINE SUAREZ: Fora desse período excepcional de pandemia, o normal é vocês se encontrarem apenas nessa reunião geral que acontece semanalmente, certo? A discussão sobre o trabalho do dia a dia se concentra mais nos meios digitais, então? Quais ferramentas vocês utilizam?

FAUSTO SALVADORI: A reunião presencial com os dez membros acontecia às segundas-feiras. Geralmente não participavam todos os dez, faltava um ou outro. No resto do tempo, só quem se encontrava presencialmente era essa equipe fixa de três jornalistas que eu mencionei. Toda a conversa acaba se dando muito no Whatsapp. Hoje em dia a gente se divide entre o Whatsapp e o Trello. O Trello foi uma benção para a gente, porque conversar no Whatsapp, fazer planejamento de pauta só no Whatsapp era um pesadelo. Hoje a gente está bem mais organizado com o Trello, a gente tem algo mais próximo de uma reunião virtual, porque muito da discussão no dia a dia se dá por Whatsapp e no Trello, embora a equipe física interaja entre si estando ali no coworking que a gente trabalha.

JAQUELINE SUAREZ: Você já trabalhou em algumas redações comerciais, já passou por outras empresas, então eu queria te perguntar se você percebe alguma diferença 


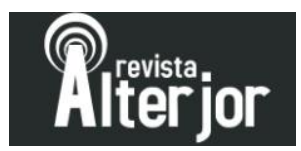

entre esses espaços e a Ponte. O que tem de parecido e de diferente, principalmente em relação ao processo de produção, de organização das pessoas e da relação entre elas?

FAUSTO SALVADORI: Só o fato de ser uma ONG já deixa tudo bastante diferente, a gente não tem o objetivo de lucro. Isso já muda muito a nossa relação. Como eu te disse, eu sou fundador da Ponte, sou uma das pessoas que mais se dedica à Ponte o tempo todo e, atualmente, eu não estou ganhando nada na Ponte, mas trabalho pra que os outros repórteres ganhem pela Ponte. Isso já dá uma diferença em relação aos outros grandes veículos, onde você explora a força de trabalho dos jornalistas e produz um lucro que vai ficar pra quem é dono. Isso é uma diferença. A nossa estrutura de organização, a maneira como a gente se organiza na Ponte, é diferente dos outros veículos na medida em que a gente não tem uma hierarquia clássica como em outras redações. A gente vai descobrindo, aos poucos, a melhor maneira de trabalhar dentro de algo que não seja a estrutura das redações tão definida como costuma ser. A gente vem construindo uma estrutura, a gente apanhou muito no começo onde a gente achava que tinha que ser totalmente horizontal e todos decidindo tudo o tempo todo. Percebemos que não funcionava dessa maneira, aí a gente começou a dividir funções, algumas pessoas são responsáveis por algumas questões e outras não. A gente criou o grupo estratégico por onde passam as principais decisões, mas mantém todo o tempo a possibilidade de todo mundo poder ser questionado, de todo o mundo poder ser ouvido sobre todas as questões. Acho que isso é uma diferença grande em relação a outras redações. A estrutura das redações no Brasil é muito hierarquizada. As redações são verdadeiros antros de assédio moral e sexual permanente, isso é um ambiente que a gente queria certamente não repetir. Não vou dizer que a gente acerta sempre, não vou dizer que a gente não tem problemas, mas a gente procura acertar e errar juntos, sempre ouvindo uns aos outros. Acho que isso é uma diferença grande em relação a outras redações onde reina o "manda quem pode, obedece quem tem juízo". Na medida do possível, na medida em que o trabalho permite, a gente tenta ter relações mais próximas da horizontalidade, mais fluídas e mais humanas. 


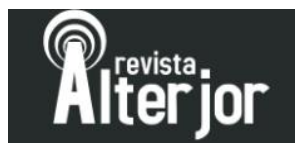

JAQUELINE SUAREZ: O fato de ser um coletivo essencialmente produzido por jornalistas faz com que a equipe conheça bastante a estrutura e os processos de uma redação tradicional. Até por essa vivência que vocês têm, me parece que a organização da Ponte parte de adaptações do modelo convencional, estou certa?

FAUSTO SALVADORI: Eu acho que no começo, como a gente tinha apanhado muito nas nossas redações de origem, a gente decidiu descartar tudo, achando que nada daquilo funcionava. Então, a gente fez uma redação onde ninguém tinha função. Todo mundo era repórter e ninguém era editor. $\mathrm{O}$ máximo que tinha, que era uma regra no começo, é que outra pessoa tinha que ler a matéria antes de ser publicada, só isso. Então, no começo a Ponte não era uma redação de verdade, a gente não estava produzindo e pensando junto, era um monte de repórter fazendo o que queria. Isso também atrapalhava a condução das pautas, atrapalhava você conseguir fazer trabalho conjunto, atrapalhava a continuidade. A gente foi percebendo, com o tempo, que nem tudo da estrutura das redações tradicionais era ruim, começamos então a resgatar algumas das técnicas tradicionais e aplicar na nossa realidade, tentando não destruir o que a gente tinha construído em termos de respeito, de respeito um com o outro e de horizontalidade dentro da Ponte. A figura do editor, por exemplo, dentro da Ponte, foi algo que durante muito tempo a gente não queria ter nada parecido, o editor é carrasco. "Morte aos editores, somos todos livres!", escrevemos o que quisermos. Com o tempo, inclusive eu que sempre fui inimigo mortal dos meus editores, odiava meus editores de maneira geral, fui vendo a necessidade. Hoje, eu assumo a função de editor na Ponte, mas foi pela percepção minha e do grupo, porque depois de tanto tempo eu comecei a pegar jeito com títulos, com lead... Depois de tanto tempo lidando com jornalismo, eu acabo tendo uma facilidade de sacar em uma história o que realmente importa nela, sacar de tudo aquilo que o repórter está falando, de toda aquela história que ele trouxe, qual realmente é o ponto de interesse. Eu percebi e o grupo foi percebendo que faz sentido ter um editor, alguém que vai ler, que vai apontar e aprovar os títulos. É uma função tradicional que a gente incorporou por perceber que fazia sentido dentro da estrutura da Ponte. E que, afinal de contas, existia motivo pelo qual depois de 200 anos 


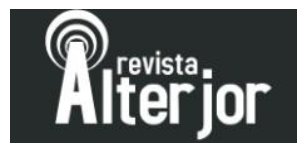

de jornalismo como a gente entende, as redações se estruturam pelos repórteres e os editores, porque, em certo sentido, esse trabalho funciona. Por que um editor é importante? É muito importante ter alguém que não está trabalhando na matéria acompanhando, porque o repórter, quando ele está trabalhando, ele só tem visão pra reportagem dele. É muito importante alguém de fora do processo olhar para a matéria e olhar para o todo, para o conjunto de matérias. Às vezes, só alguém que está do lado de fora consegue ver o que que é mais importante, qual notícia merece ser derrubada. Mas foi depois de bater muita cabeça que a gente percebeu isso. A gente começou com um grupo totalmente horizontal, sem nenhuma função definida e, com o passar do tempo, fomos incorporando algumas funções tradicionais por perceber que elas funcionavam e melhoravam o processo. Então, a gente resgata a figura do editor, do editor geral e até a figura do pauteiro. O que acontecia algumas vezes? Todo mundo trabalhava fazendo tudo e chegava numa reunião semanal, havia um descontentamento geral. Por que a gente deu essa história se aquela outra era tão importante? Por que a gente deu esse título que não funciona nessa matéria? Ninguém sabia o motivo. É muito chato você ser cobrado por uma coisa que você não sabia direito como era, que ninguém te falou como era. Quando você traz as funções, as tarefas ficam mais claras, cada um sabe o que faz, isso ajuda as pessoas a se organizarem e a trabalharem melhor.

JAQUELINE SUAREZ: Quando vocês dizem que a Ponte Jornalismo é uma mídia independente, vocês estão dizendo que ela tem determinadas características, que ela é de uma forma e não de outra. Eu queria entender porque o uso desse termo - mídia independente? Na sua avaliação, qual o significado disso?

FAUSTO SALVADORI: Bom a gente usa esse termo porque é um termo consagrado, né? Quando você cita esse termo, as pessoas tem uma ideia do que você está falando mais ou menos. E, se falasse nativo digital, um termo que eu pessoalmente prefiro, acho mais preciso, as pessoas não entenderiam direito sobre o que você está falando. Eu acho que o termo mídia independente engloba coisas muito diferentes... Tem veículos muito diferentes sob esse guarda-chuva, você tem empresas grandes, você tem veículos bem 


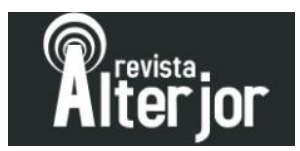

menores, e sem fins lucrativos, então diria que sob esse guarda-chuva de independente tem veículos bastante diferentes um dos outros usando o mesmo guarda-chuva. Aliás, tão diferentes que eu acho que chega uma hora que esse rótulo já não significa muita coisa. Se você coloca um grupo como a Lupa por exemplo, um veículo independente, feito por jornalistas de grande imprensa, que nasceu dentro da Globo, apoiada por grandes empresários, que vende conteúdo, que tem objetivo de lucro e você coloca esse grupo nesse mesmo rótulo que a gente? Tem alguma afinidade, somos pequenos, tem a questão do nativo digital, ou seja, grupos que surgiram na internet, surgiram por causa da internet, muitos deles criados por jornalistas, com o modelo pensado a partir do jornalismo. Então, acho que isso é algo que todos eles têm em comum, apesar de toda a diversidade. Quando se fala que é independente você entende que, digamos assim, você não está servindo aos grandes grupos capitalistas. Você não está servindo ao grande negócio, pelo menos, se imagina isso. Você não está ligado aos grandes poderes, a grande mídia mainstream, não depende de anunciantes, não depende dos grandes conglomerados, das grandes corporações, acho que essa é um pouco a ideia do independente. É complicado porque nem todo veículo que se diz independente cabe nessa definição. No nosso caso, a gente se diz independente, a gente é um veículo criado por jornalistas, pensado dessa maneira, sem ligação nenhuma com grandes grupos econômicos, sem nenhuma ligação com partidos políticos, sem nenhuma ligação com governos e com uma postura muito crítica em relação a toda a maneira como a segurança pública é organizada no Brasil. Então, dessa maneira, a gente se coloca numa posição muito independente e muito crítica em relação a outros veículos de comunicação que a gente conhece. Nesse sentido, acho que seria o que a gente pode chamar de independente. O problema de quando você começa a usar muito o termo, a pensar muito nesse conceito, ele te leva a várias armadilhas. A gente tem dinheiro da Open Society, por exemplo, a gente tem dinheiro do Yahoo, que compra nosso conteúdo, a gente depende deles, então até que ponto a gente pode se dizer independente? A rigor, nenhum veículo é independente de verdade porque algum dinheiro sempre vai vir de algum lugar. Ah, mas tem independência editorial? Sim, mas até aí muito veículo tem independência editorial, no sentido de não precisa deixar 


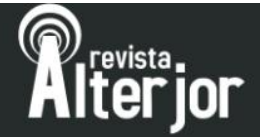

aquele que paga editar seu conteúdo. Eu acho que quando você começa a espremer muito o conceito de mídia independente ele te leva a essas armadilhas. Só seria realmente independente se essa mídia existisse realmente livre, no ar, sem depender de ninguém ou se fosse feito por milionários que não precisam pedir remuneração de ninguém, digamos assim. Então, você sempre vai dependente de alguém em certo sentido.

\section{REFERÊNCIAS}

QUEM SOMOS. Ponte Jornalismo. Disponível em: https://ponte.org/sobre/autores/. Acesso em 01/11/2020.

SALVADORI, Fausto. Entrevista concedida a Jaqueline Suarez Bastos em $\mathbf{1}^{\mathbf{o}}$ de maio de 2020, por vídeo-chamada. Arquivo em vídeo ( $2 \mathrm{~h} 46 \mathrm{~m} 40 \mathrm{~s})$. 